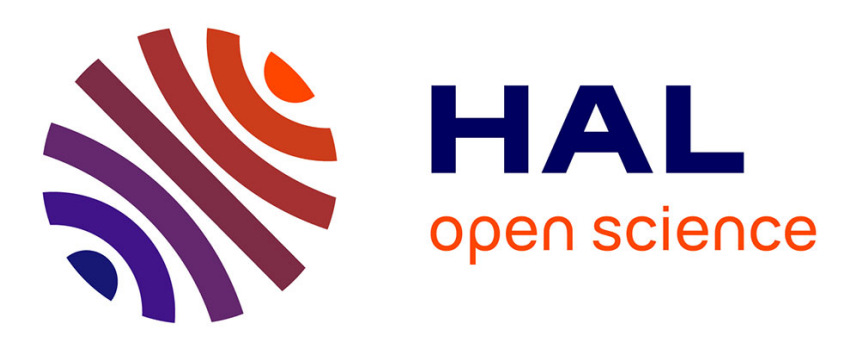

\title{
Is smiling during humor so obvious? A cross-cultural comparison of smiling behavior in humorous sequences in American English and French interactions
}

Béatrice Priego-Valverde, Brigitte Bigi, Salvatore Attardo, Lucy Pickering, Elisa Gironzetti

\section{To cite this version:}

Béatrice Priego-Valverde, Brigitte Bigi, Salvatore Attardo, Lucy Pickering, Elisa Gironzetti. Is smiling during humor so obvious? A cross-cultural comparison of smiling behavior in humorous sequences in American English and French interactions. Intercultural Pragmatics, 2018. hal-01923442

\author{
HAL Id: hal-01923442 \\ https://hal.science/hal-01923442
}

Submitted on 15 Nov 2018

HAL is a multi-disciplinary open access archive for the deposit and dissemination of scientific research documents, whether they are published or not. The documents may come from teaching and research institutions in France or abroad, or from public or private research centers.
L'archive ouverte pluridisciplinaire HAL, est destinée au dépôt et à la diffusion de documents scientifiques de niveau recherche, publiés ou non, émanant des établissements d'enseignement et de recherche français ou étrangers, des laboratoires publics ou privés. 


\title{
Is smiling during humor so obvious? A cross-cultural comparison of smiling behavior in humorous sequences in American English and French interactions
}

Béatrice Priego-Valverde

Aix Marseille Univ, CNRS, LPL, Aix-en-Provence, France

beatrice.priego-valverde@univ-amu.fr

\section{Brigitte Bigi}

Aix Marseille Univ, CNRS, LPL, Aix-en-Provence, France

brigitte.bigi@lpl-aix.fr

Salvatore Attardo

Applied Linguistics Laboratory, Texas A\&M University-Commerce, USA

Salvatore.Attardo@tamuc.edu

Lucy Pickering

Applied Linguistics Laboratory, Texas A\&M University-Commerce, USA

Lucy.Pickering@tamuc.edu

\section{Elisa Gironzetti}

University of Maryland, USA

elisag@umd.edu

\begin{abstract}
The present article is part of a larger cross-cultural research project on speaker-hearer smiling behavior in humorous and non-humorous conversations in American English and French. The American corpus consists of eight computer-mediated interactions between English native speakers, and the French one consists of four face-to-face interactions between French native speakers. The goal of the study is twofold: first, we analyze the link between smiling and humor, focusing on the degree of synchronicity of smiling and the intensity of smiling during humorous and non-humorous segments; second, we investigate the various targets mobilized in conversational humor. The results obtained comparing the two data-sets show a correlation between the presence of humor, an increased smiling intensity, and an increase in the synchronized smiling behaviors displayed by participants. However, the two corpora also differ in terms of the displayed smiling behaviors: French participants display more nonsynchronic smiling when humor is absent and more synchronic smiling when humor is present. Regarding the various targets of humor (Speaker, Recipient, Other person, Situation, Speaker + Recipient), while their distribution is different $\ddot{i}$ it is more evenly distributed in the French data $\ddot{i}$ the way in which these are mobilized in order to become humorous is quite similar.
\end{abstract}

Keywords: Smiling behavior, cross-cultural comparison, conversation, synchronicity, humor target. 


\section{Introduction}

This article is the first attempt to compare the results previously obtained separately in previous studies carried out on an American corpus on the one hand (Gironzetti, Pickering, Huang, Zhang, Menjo and Attardo 2016, and Gironzetti, Attardo, and Pickering 2016), and on a French corpus on the other hand (Priego-Valverde and Bigi 2016, Priego-Valverde 2017). In the context of a cross-cultural comparison of conversational humor in two languages, American English and French, the aim of the present study is twofold: Firstly, we investigate the links between conversational partnersôsmiling behavior and humor; secondly, we analyze more precisely the functioning of conversational humor through the various targets present in the utterances.

After a brief overview of research on smiles in conversation, we will present our two corpora and the various tools used for analyzing both smiles and humor. Our comparative analysis will be divided into four parts. The first one will be dedicated to the analysis of canned jokes, highlighting the various reactions to them (mainly from success in the American data to failure in the French data). In the second part, we will compare American and French participantsô synchronized smiling behaviors, linking them to the presence or absence of humor. Then, we will compare the distribution of five targets of a humorous utterance (the speaker, the recipient, another absent person, the situation and both the speaker and the recipient). While we mainly propose quantitative results in these three parts, in the last one, we will present a sequential analysis of some examples of conversational humor, focusing on two targets: ñSpeaker + Recipientò, and ñOtherò.

\section{Brief overview of the literature}

\subsection{Smiling in conversation}

Studies on smiling in conversation can be divided into two categories. The first and predominant one analyzes smiling with an emotional perspective, considering smiling as a ñfacial expressionò (Bavelas, Gerwing and Healing, 2014) connected with positive emotions such as joy (see Ekman, Sorenson and Friesen, 1969; Izard 1997; Elfenbein and Ambady 2002; Ekman 2007). The second type of study $\ddot{i}$ with which this article is in line $\ddot{i}$ considers smiling as a ñconversational facial gestureò (Bavelas et al. 2014) in order to highlight ñ close functional similarities to conversational hand gesturesò (Bavelas et al. 2014: 18). These kinds of studies focus thus on the various functions of smiling in conversation: a backchannel signal (Brunner 1979, Duncan, Brunner and Fiske 1979, Argyle 1988, Jensen 2015), an affiliative device (Niedenthal, Krauth-Gruber and Ric, 2006), or a way to frame discourse in different ways, for examples, as delicate (Haakana 2010) or as humorous (Coates 1991, Haakana 2010, Kaukomaa, Peräkylä, and Ruusuvuari 2013, Gironzetti, Pickering, Huang, Zhang, Menjo and Attardo 2016; Gironzetti, Attardo, and Pickering 2016).

\subsection{Smiling and humor in conversation}

Links between laughter and humor have been regularly mentioned since the seventies in Conversation Analysis. Considered as a marker of humor by Sacks (1974), laughter was studied by Jefferson (1979) as a device used by the speaker to show his/her humorous intention in a conversation. In line with such studies, some authors even claimed that laughter 
is áne contextualization cue for humor par excellenceô̂(Kotthoff 2000: 64), and its lack is seen as a mark of failure of humor (Norrick 1993).

However, many researchers in the field of humor studies agree that the relationship between laughter and humor is questionable. Firstly, humor does not necessarily trigger laughter and laughter is not always provoked by humor (see Attardo 1994, Chapman and Foot 1996, Morreall 2001, Priego-Valverde 2003). Secondly, it has been shown that not only does the lack of laughter not necessarily mean that humor has failed, but it can also be seen as a support strategy (Hay 2001). Finally, analyzing the links between humor and laughter without taking into consideration the emotional dimension of laughter can only lead to an incomplete answer. Thus, research on negative emotions triggered by humorous incongruity (see Morreall, 1983, Lewis 1989, Schulz 1996) highlighted the complex function of laughter which can show recognition of humor without any appreciation of it.

\subsection{Smiling reciprocity}

Research on behavioral synchrony (see Fusaroli and Tylén 2012) includes smiling as a subfield. From this perspective, previous research on smiling has shown that conversational partners reciprocate each otherô smiles (Cappella 1997, Hess and Bourgeois 2010, Wild et al. 2003) and expect others to do the same, otherwise perceiving the partner as aversive and not willing to communicate (Cappella 1997, Heerey and Kring 2007, Heerey and Crossley 2013). Moreover, research on interpersonal alignment showed that speakers tend to ñchange their affect, behavior, and cognition as a direct result of their interaction with another individualò (Paxton and Dale 2013: 1).

Smiling synchronicity was recently studied in relation with the presence or absence of humor, highlighting the function of ñframingò smiling. In (Attardo et al. 2013: 411), the authors hypothesized that ña manifestation on the smile-laughter continuum was used to órameôa segment of the discourse as humorousò. This hypothesis has been deepened by Gironzetti et al. (2016: 13-14) adding the role of the synchronicity of smiles: ñThus, it is possible that participants having a humorous conversation would smile at the same time and at the same intensity, on average higher than when humor is not present, in order to frame the exchange as humorous.ò This ñframingò role has also been highlighted in a French corpus (PriegoValverde and Bigi 2016; Priego-Valverde 2017).

\section{Corpus and methodology}

\subsection{Presentation of the two corpora}

The two corpora were collected in order to analyze both canned jokes and conversational humor, following the protocol established in Attardo et al. (2011). The participants were asked to tell each other a canned joke chosen by the researchers, before conversing as freely as they wished for the rest of the interaction. Consequently, although the setting played a role on some occasions, the participants regularly forgot that they were being recorded, to the extent that they reminded each other that they were being recorded when one of the participants started talking about quite an intimate topic. Even though the two corpora are similar enough to offer a cross-cultural comparison of humor, they also show some relevant differences for the present study. Therefore, we will present them separately. 
It is worth noting here that the instances of canned jokes and conversational humor present in both data were analyzed without taking into account sociolinguistics information concerning the participants, as gender or age.

\subsubsection{The American corpus}

The participants of the eight interactions presented here were students in the same class of a Midwestern university in the USA. All were native speakers of American English and all signed a written consent form before the recordings. The dyadic interactions were audio and video recorded. Participants were interacting using video-chat software; two audio and video recordings (one per participant) were made per conversation. Each interaction lasted approximately five minutes. The data were collected using video-chat to provide a nonintrusive way of recording close-up video and miked audio, since the participants were familiar with video-chatting, a widely-available technology. Furthermore, video-chatting reduces the probability of loss of data due to excessive changes in posture, since the speakers are aware of the need to remain in the video angle of the camera. Further research (Gironzetti 2017) has shown that there are no significant differences in humor performance across the video chat and the face-to-face conditions.

The audio and video files were aligned with ELAN (Brugman and Russel 2004), which also allowed for creating different tiers and annotating different types of information: orthographic transcription, prosodic features, smiling intensity coding, smiling synchronicity coding, and humor coding. Prosodic features of conversations were measured using CSL (Computerized Speech Lab). All the quantitative data were calculated with Excel.
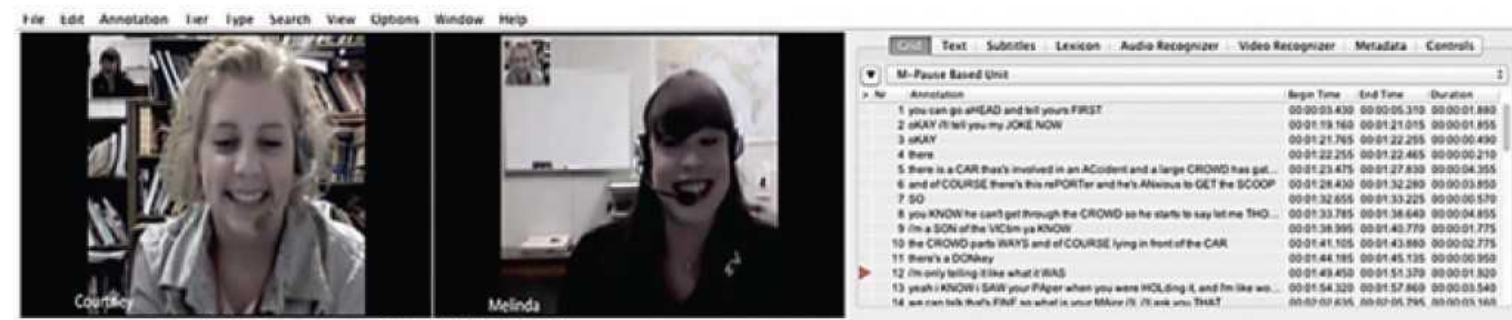

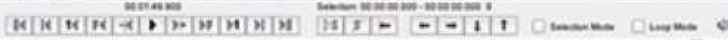

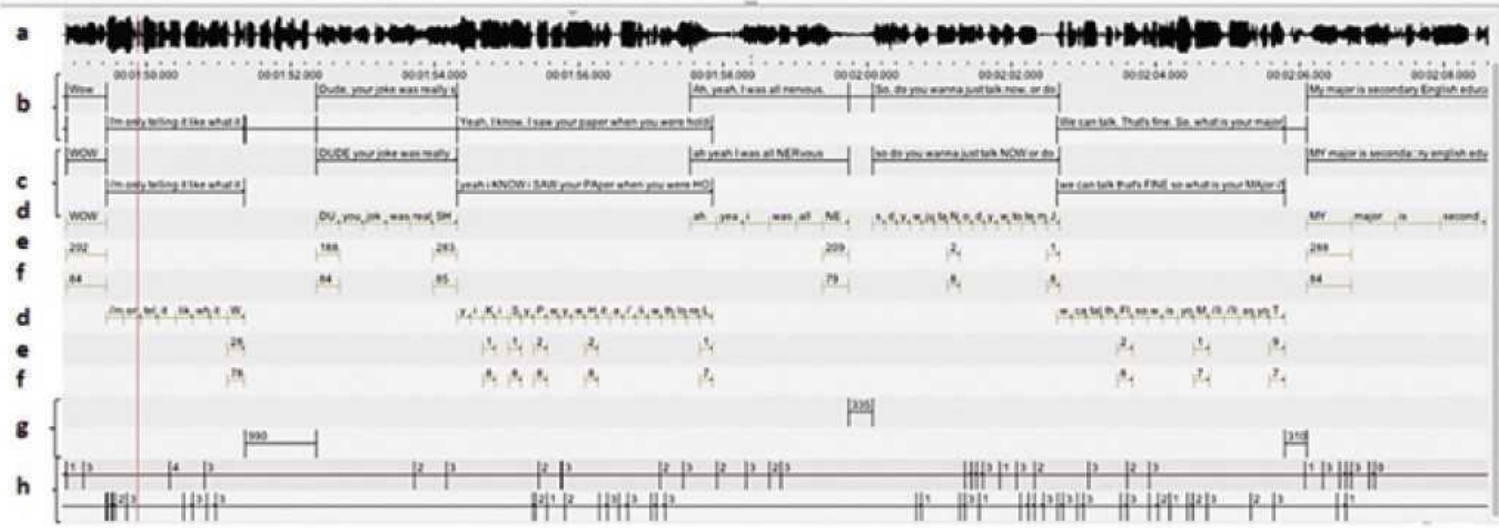

Figure 1. ELAN interface for corpus alignment and annotation (from Gironzetti et al. 2016) 
(a) audio waveform of the conversation (just one audio file was used),

(b) paused-based unit transcription of each participantôs speech,

(c) orthographic transcription for each pause-based unit for each participant,

(d) smiling intensity for each participant.

Finally, a ñwindowò of five seconds (two seconds before the humorous utterance and three seconds after), was isolated. The length of the ñwindowò of sampling was established following Ekmanôs result that facial expressions typically last between 0.5 and 4 seconds (Ekman 2003: 217). By allowing for a window of 5 seconds, the protocol essentially ensured that any facial expression before and after the humorous instance would be captured.

\subsubsection{The French corpus}

In order to compare humorous behaviors of the participants in both cultures, the French corpus has been recorded in respect with the American protocol, as far as possible. The participants of the four interactions presented here were students in the same class at AixMarseille Université (France), and French native speakers. They all signed a written consent form before the recordings. Most importantly, they all received the same task as the American participants. Finally, the two same jokes were translated and used in order to see the impact of the culture on the comprehension and / or appreciation of the jokes.

The major difference between the American and the French corpus concerns the protocol: the French interactions are face-to-face interactions audio and video recorded in the anechoic room of the Laboratoire Parole et Langage (Aix-en-Provence, France). They were recorded with two cameras and two headphones and lasted around 15 minutes each.

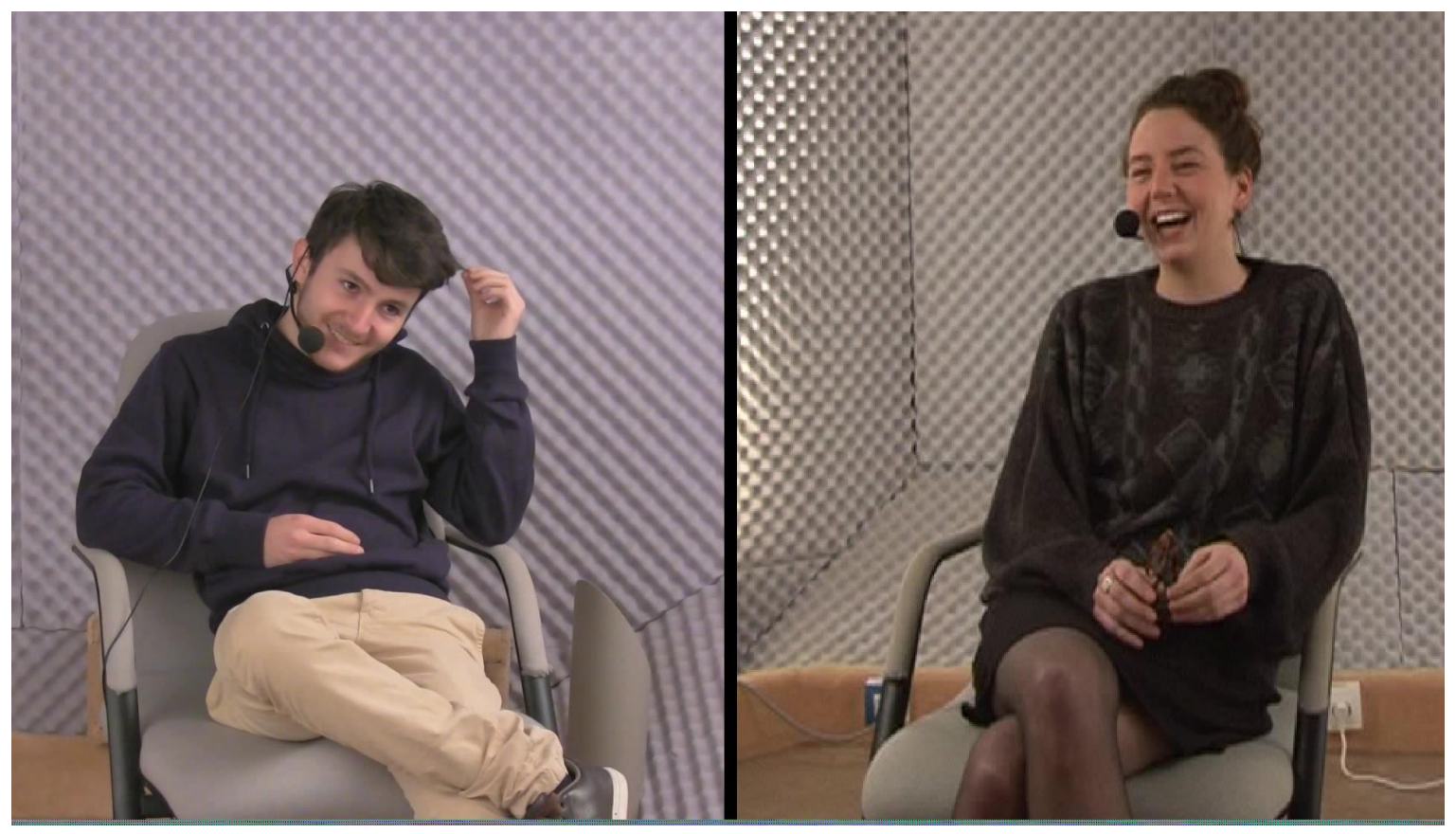

Figure 2. Two face-to-face participants 
Concerning the data processing, each audio signal was firstly automatically segmented in Inter-Pausal Units (henceforth, IPUs) i.e. blocks of speech bounded by silent pauses over 200 $\mathrm{ms}$, and time-aligned on the speech signal. Smiling intensity was manually annotated with ELAN while smiling synchrony was automatically extracted based on the observation of the intensity values of each participant. The humorous utterances were manually annotated with PRAAT (Boersma 2002). In addition to ELAN and PRAAT, we also used the software SPPAS (Bigi, 2015), for the segmentation in IPUs and the transcriptions of the audio files. We also used SPPAS to merge all the annotations, to perform the requests (Bigi and Saubesty 2015), and to estimate the descriptive statistics. In other words, the same tasks and requests have been done on the two corpora, the only difference consisting partially in the software used.

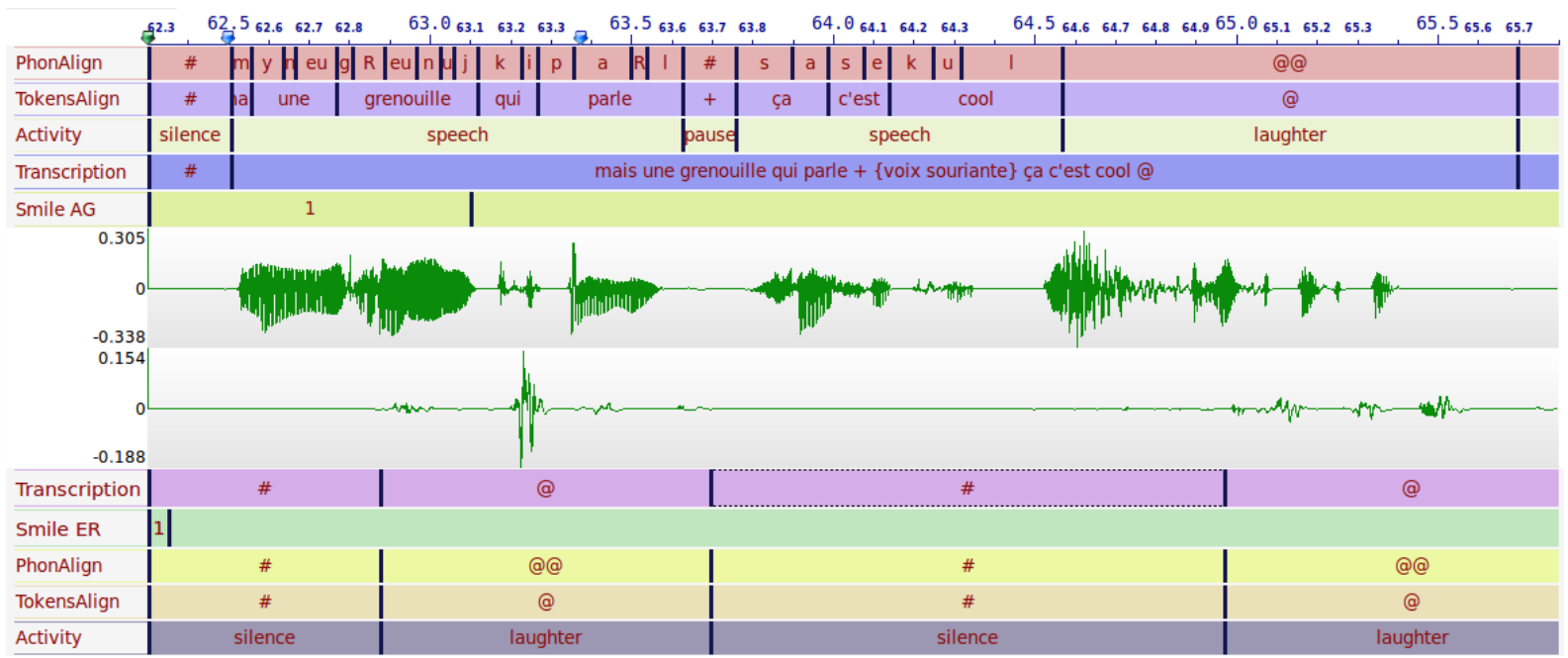

Figure 3. SPPAS interface

\subsection{Tools used to measure smiling behavior}

\subsubsection{Smiling Intensity Scale}

The five levels of the Smiling Intensity Scale (SIS) are descriptive of different smiling behaviors:

- Level 0: Neutral. No smile, no flexing of the zygomaticus.

- Level 1: Closed mouth smile. Shows flexing of the zygomaticus, may show dimpling and may show flexing of the orbicularis oculi.

- Level 2: Open mouth smile. Showing upper teeth, flexing of the zygomaticus, may show dimpling, may show flexing of the orbicularis oculi.

- Level 3: Wide open mouth smile. Shows flexing of the zygomaticus, flexing of the orbicularis oculi, and may show dimpling.

- Level 4: Laughing smile. The jaw is dropped, showing lower and upper teeth, flexing zygomaticus, flexing of the orbicularis oculi, dimpling. 

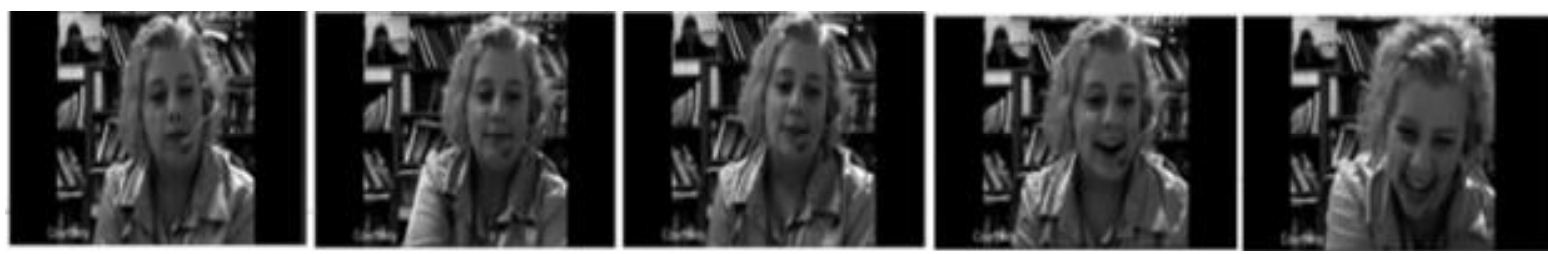

Figure 4: The Smiling Intensity Scale (from Gironzetti et al. 2016)

\subsubsection{Smiling synchronicity}

The smiling synchronicity categories (Gironzetti et al. 2016) are inferred from the Smiling Intensity Scale and coded according to the following descriptions:

- Value -1: non-smiling synchronic behavior. Both participants display a smiling 0 on the SIS.

- Value 0: smiling asynchronic behavior. One participant displays a smile 0 while the other displays another smile behavior.

- Value 1: smiling synchronic behavior without intensity matching. Both participants display a smiling behavior superior to 0 but not at the same intensity.

- Value 2: smiling synchronic behavior with intensity matching. Both participants display the same smiling behavior, at the same intensity.

\section{The General Theory of Verbal Humor}

The General Theory of Verbal Humor (Henceforth, GTVH, Attardo and Raskin 1991, Attardo 2001) provides semantic/pragmatic criteria stable enough to reduce as far as possible the subjectivity of the analysts while identifying the humorous utterances, which is helpful due to the fact that we will study conversational humor in two different languages. ${ }^{1}$

Revised and extended version of the Semantic Script Theory oh Humor (SSTH) proposed by Raskin (1985), the GTVH presents the several components of a text to be humorous. These components are named ñKnowledge Resourcesò (Attardo 2001: 22). In this article, we will focus on one of them: the ñTargetò, hence, proposing an extension of the GTVH. In the original version, the target is presented as the r̃ buttò of the joke (Attardo 2001: 23). In other words, the aggressiveness of humor is always implied. However, our data showed that even if humor is always oriented toward a participant of the interaction (the speaker him/herself, the hearer, a third absent person, or toward the setting / situation), this does not always imply aggression toward them (and hence making them a target, per the GTVH). Considering that the term ñargetò does imply aggressiveness, we will use the terms ñspeaker/other-oriented humorò instead of ñspeaker/other denigrating humorò, following Béal and Mullan (2013, 2017). Orientation of the humor is not part of the original GTVH and thus introducing this distinction is an extension of the GTVH. Below, one example of orientation is presented. It comes from the French data and the two participants are talking about the setting, i.e. the anechoic room:

\footnotetext{
${ }^{1}$ For further discussion of integrating the GTVH in a triangulation method to identify humor in conversation, see Attardo (2012).
} 
(1) CL 46 tôas pas lồmp

Donâ you have the imp

CL47@ @ @ressiondôêtredans une@@boitedônufs

@@pression@@ of being in a@@ eggs box

JS $42 @$

CL48@

CL49@

JS43@@avec lespetits@@

@@with the small@@

JS44@@@@

CL50@

\section{Comparative analyses of the data}

\subsection{The canned jokes}

Most of the canned jokes ${ }^{2}$ succeeded in the American data, see (1), at least to the point that they were recognized as jokes, even though the tellers commented in some cases about the poor quality of the joke. We will therefore focus our analysis on the French ones, but see M and Jô joking about the poor quality of the donkey joke in section 9.5.

(2)

\begin{tabular}{|c|c|c|}
\hline 69 & $M$ & 0.731 \\
\hline 70 & & $/ / L O O K / /$ \\
\hline 71 & & 0.207 \\
\hline 72 & & //i'm an engiNEER \\
\hline 73 & & i donô have TIME \\
\hline 74 & & for a GIRLfriend// \\
\hline 75 & & 0.539 \\
\hline 76 & & //but a talking FROG \\
\hline 77 & & now THAT'S cool// \\
\hline 78 & & 0.596 \\
\hline 79 & & //the end// \\
\hline 80 & $J$ & $((\operatorname{laughs}))$ \\
\hline 81 & & 0.36 \\
\hline 82 & $M$ & $(($ laughs $))$ \\
\hline 83 & $J$ & //wow THAT was \\
\hline 84 & & really FUnny// \\
\hline 85 & & 0.428 \\
\hline 86 & $M$ & //yeah i KNOW \\
\hline 87 & & that's what $i$ THOUGHT// \\
\hline 88 & & 0.706 \\
\hline
\end{tabular}

The two jokes were perceived differently in the French data. While the ñfrog jokeò was a relative success, the ñdonkey jokeò was clearly a failure due to a cultural issue. The link between the absence of a shared negative stereotype and the failure of the joke will be highlighted with the GTVH.

\footnotetext{
${ }^{2}$ See annex for the original jokes and the transcription conventions.
} 


\subsubsection{The ñfrog jokeò}

This joke concerns an engineer. The stereotypes for ñengineer,ò on which the joke is built, are different in the United States and France. In France, engineers are generally associated with a high level of education, and are seen as clever and serious. Conversely, in the United States, an engineer is seen as a person with limited social skills and only interested in his/her computers. In other words, the American stereotype of the engineer corresponds to the French stereotype of the ñgeekò. Therefore, the joke would have been probably more appreciated if the term ñgeekò had been used.

The first reason for the relative success of this joke is its funniness, as it is expressed by an American participant in (2). For French people, the Logical Mechanism (Attardo 2001) consisting in activating a world where a frog can speak, is also perceived as funny.

\section{AD 320 une grenouille qui parle euh \{voix souriante\} c'est cool quoi c'est amusant tu vois genre euh voilà tu vois euh}

á speaking frog uh \{smiling voice $\}$ well itôs cool itô funny you see like uh so you see uhô

The second reason is the fact that the participants seem to be able to identify with the engineer, as in (3).

(4) AG $33 \quad$ ok @ franch(e)ment j(e) préfère mon histoire de grenouille

ók @ frankly I prefer my frog storyô

AG 34 elle est plus mignonne et puis on sộ

ótôs more cute and weô

AG $35 \quad$ identifie plus

\section{ốdentify with it moreô}

However, although the fact that the participants were able to identify the joke can explain its relative success, it also and above all highlights the fact that French participants did not understand what the point was for American people, i.e. the stereotype of such an anti-social person that he prefers to be accompanied by a speaking frog rather than a princess. For instance, $\mathrm{AD}$ associates the engineers with a frbusy guyò. In other words, while the American participants can make fun of the engineers, the French cannot.

But despite its relative success, the frog joke failed in one interaction (MA_PC). As the engineers do not transmit any negative cultural stereotypes, MA could not identify the humor, therefore, the punchline when it appears and was still expecting a follow up after its ending.

$$
\text { PC } 33 @ \text { @asyà@@àtoi@@ }
$$




\section{ó@go ahead@@yourturn@@ô \\ MA25@@@ốtsfinî̂@@ \\ ó@@youôre finishedŷy@ô}

\subsubsection{The ñdonkey jokeò}

This joke failed in most French conversations, and three reasons can explain why. The first reason seems to be the presentation of the task itself. While the jokes were translated into French, their titles were not, and the term ñdonkeyò was sometimes not understood, see (5), even if the word donkey was translated in the text itself.

(6) MD $38 \quad$ côsst quoi donkey déjà $\uparrow$

óvhatôs donkey [mean] again $\uparrow$ ô

\section{$A D \quad 74 \quad$ donkey côst le singe}

\section{álonkey itô the singe [monkey]ô}

The second reason concerns the way the journalist is staged in the joke. For French people, the stereotype represented in the joke concerning a man ready to do anything in order to have a scoop better represents the paparazzi (which is evocated by one of the participants, AD), rather than a journalist. For this reason, the presence of the journalist did not activate any Script Opposition (Raskin 1985; Attardo 2001), and therefore the joke did not make sense and was in fact illogical for the French participants. The example (7) where AD tries to understand why the joke should be funny shows that.

(7) $\quad A D \quad 17 \quad$ donc on a une voiture

Q́o we have a carô

AD 18 et on a

ánd we haveô

MD 25 ben allez juste parle euh

ávell go on then just speak uhô

$A D \quad 20 \quad$ un journaliste

á journalistô 
The last reason for the failed joke can be explained by the Narrative Strategy, since, like for the frog joke, one of the participants here also did not understand the punch line and the end of the joke in (7).

(8) JS $34 \quad$ il y avait

áhere wasô

JS $35 \quad$ \{voix souriante\} un âne

ó smiling voice $\}$ a donkeyô

CL $34 @$

ó@ô

JS 36@@@@d'accord@@

ó@@@allright@@ô

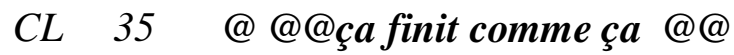

ó@@@it ends like thisŷ@@ô

5.2 General synchronic smiling behaviors of participants

\subsubsection{American data}

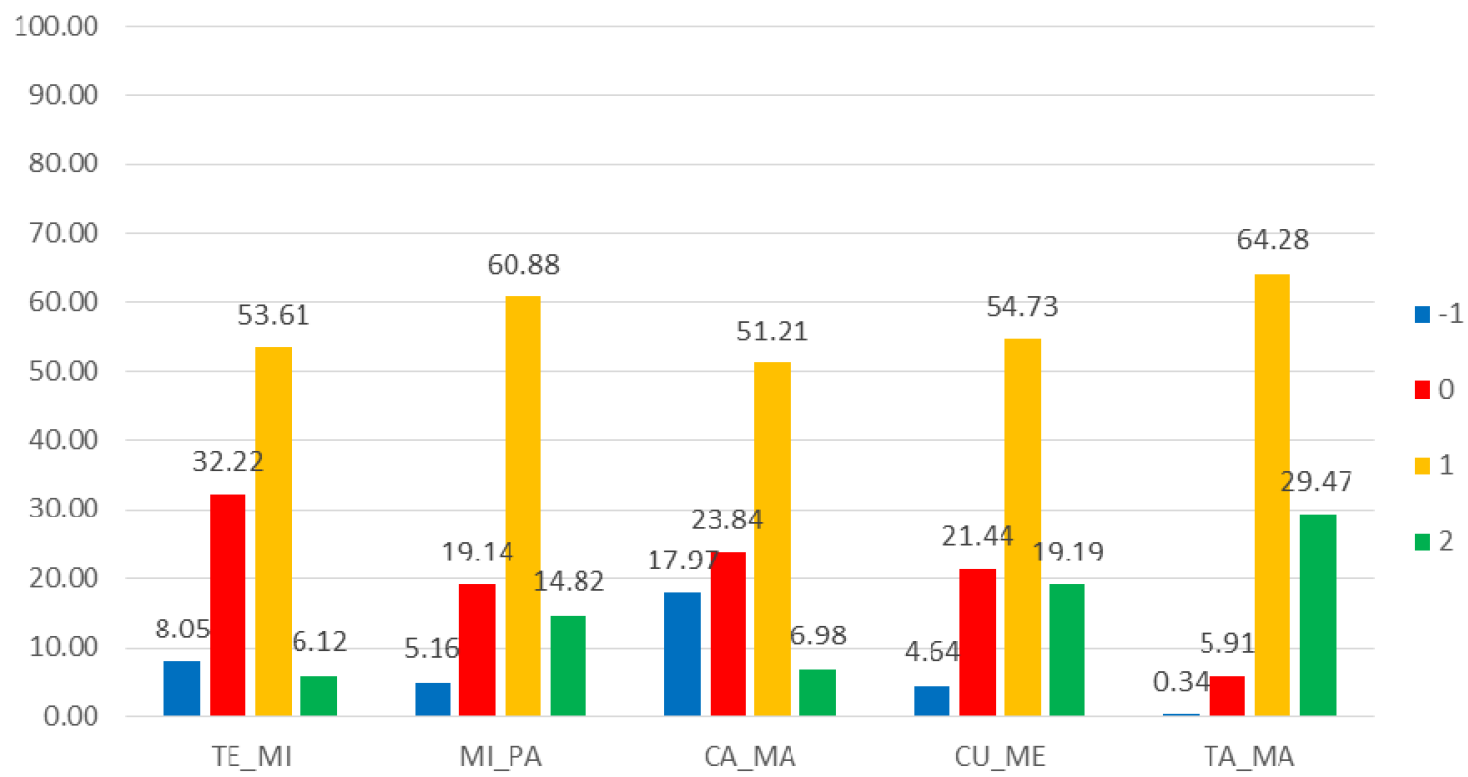

Figure 5. Duration of different smiling synchronicity for five dyads (from Gironzetti et al. 2016) 
Without distinguishing the humorous segments from the non-humorous, a heterogeneous smiling behavior can be observed. The ten participants display different levels of smiling synchronicity, covering a range from 93.75\% (TA_MA), to 58.19\% (CA_MA). Overall, when comparing smiling synchronicity, participants displayed a synchronic smiling behavior (combination of behaviors 1 and 2) for $66.77 \%$ of the time, matching each otherôs smiling intensity (behavior 2) for $11.45 \%$ of the time.

\subsubsection{French data}

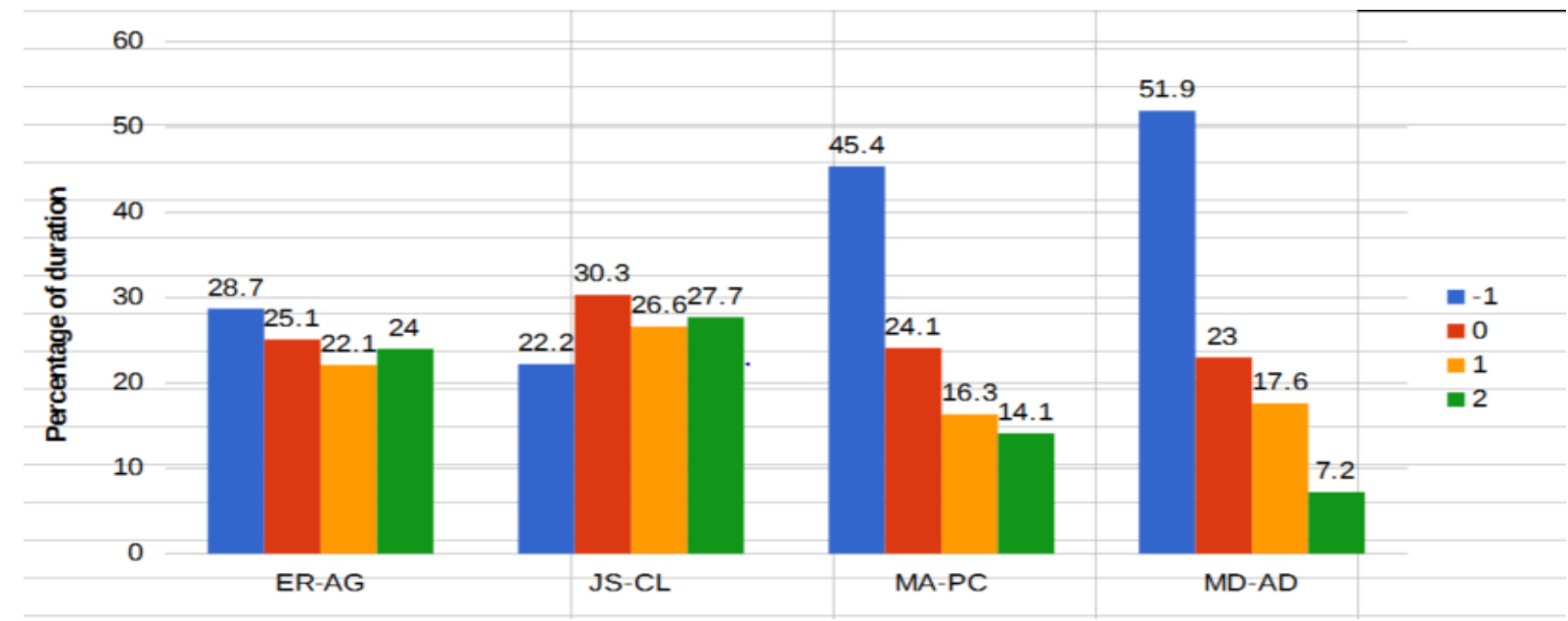

Figure 6. Duration of different smiling behaviors for four dyads

In the French data, the participantsôsynchronic smiling behaviors (behaviors 1 and 2) are also heterogeneous, but to a lesser extent. For behavior 1, the range varies from 16.3\% (MA_PC), to $26.6 \%$ (JS_CL). The major fluctuation concerns behavior 2: from $7.2 \%$ (MD_AD) to $27.7 \%$ (JS_CL). Concerning the combination of behaviors 1 and 2, the participants display a synchronic smiling behavior from $24.8 \%$ (MD-AD) to $54.3 \%$ (JS_CL), which is a more homogeneous result than the American data.

\subsection{Synchronic smiling behavior for humorous and non-humorous segments}

\subsubsection{American data}




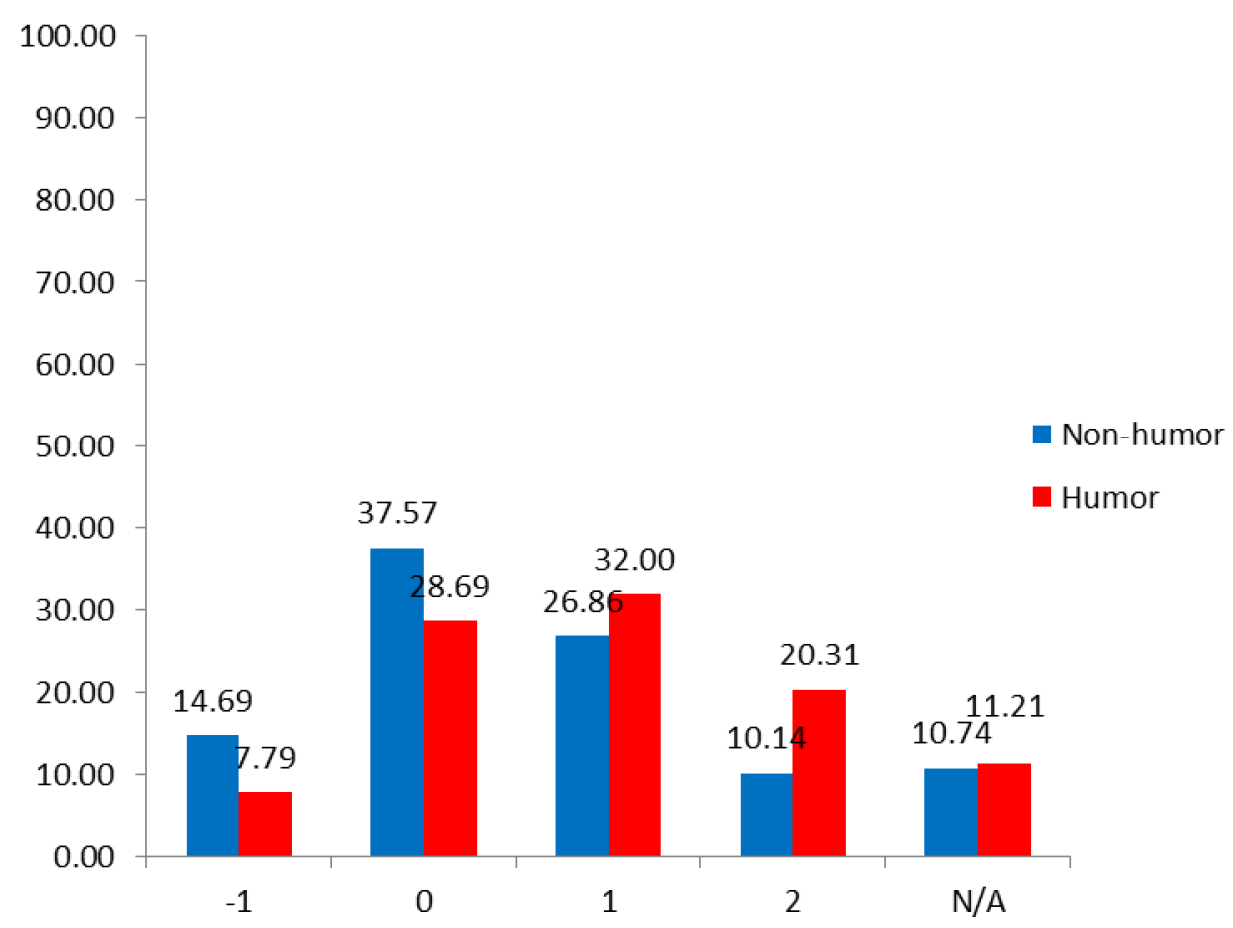

Figure 7. Smiling synchronicity across humorous and non-humorous sequences (from Gironzetti et al. 2016)

When examining smiling synchronicity for humorous and non-humorous segments, a different picture emerges. The figure above combines the values obtained from each pair of participants, and displays values (in milliseconds) of smiling synchronicity for each behavior across humorous and non-humorous sequences. The percentages refer to the amount of time spent displaying each behavior during humorous and non-humorous segments separately. Thus, participants spend $8 \%$ of the time when humor is present displaying a non-smiling synchronic behavior while they spend $15 \%$ of the time when humor is not present displaying a non-smiling synchronic behavior. Moreover, participants spend more time displaying the facial expression 0 or $і ̈ 1$ during non-humorous sequences than during humorous sequences, while they spend more time displaying facial expressions 1 and 2 during humorous segments than during non-humorous segments.

Comparing humorous and non-humorous sequences, it emerges that there is a general increase of smiling synchronicity and a general decrease of smiling non-synchronicity during humorous segments of conversation. More specifically, the percentage of time for behavior 2 doubles during humorous segments (Non-humor $=10 \%$, Humor $=20 \%$ ), while the percentage for behavior 1 increases only slightly (Non-humor $=27 \%$, Humor $=32 \%$ ).

On the other hand, the percentage of time for behavior 0 and behavior $і 11$ decreases during humorous segments (Behavior -1 : Non-humor $=15 \%$, Humor $=8 \%$; Behavior 0: Nonhumor $=37 \%$, Humor $=29 \%$ ). Overall, synchronic smiling behaviors occur $52 \%$ of the overall time during humorous segments, but only $37 \%$ of the time during non-humorous segments. The comparison of humorous and non-humorous segments shows that there is a general increase of smiling synchronicity (1 and 2) and a general decrease of smiling nonsynchronicity ( 0 and $i$ ) during humorous sequences. 
Finally, it is worth noting that the percentage of missing data (group N/A), which is due to participants covering their face or moving outside of the area recorded by the cameras, is constant across humorous and non-humorous segments

\subsubsection{French data}

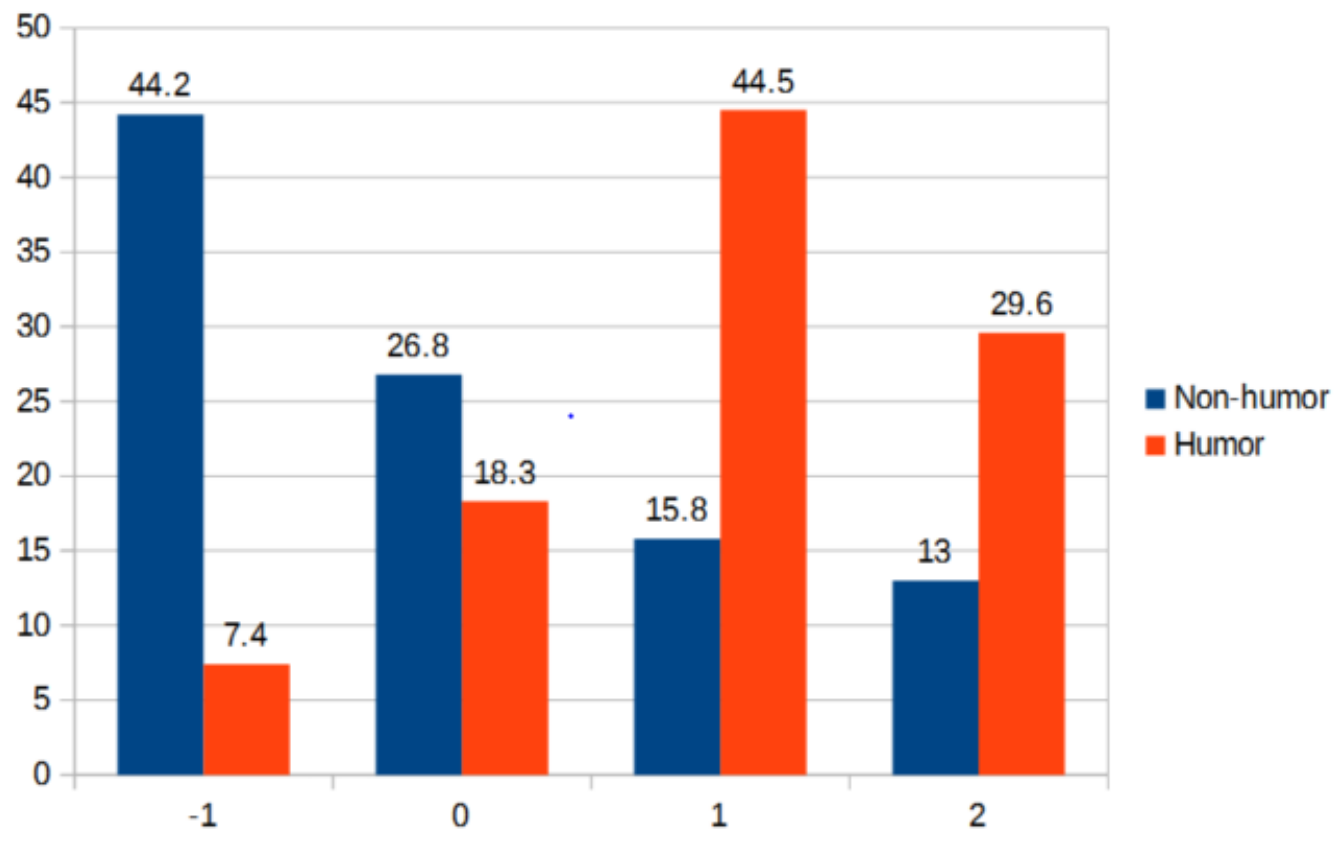

Figure 8. Smiling synchronicity across humorous and non-humorous sequences

Figure 8 shows that the French participants spend $7.4 \%$ of the time when humor is present displaying a non-smiling synchronic behavior while they spend $44.2 \%$ of the time when humor is not present displaying a non-smiling synchronic behavior. Moreover, during nonhumorous segments, participants spend more time at 0 , displaying a smiling asynchronic behavior or at $\ddot{i} 1$, displaying a non-smiling synchronic behavior, than during humorous segments, while during humorous segments they spend more time at 1 and 2 , displaying a smiling synchronic behavior without intensity matching for the former, and with intensity matching for the latter, than during non-humorous segments of conversation.

Comparing humorous and non-humorous sequences, it emerges that there is a general increase in smiling synchronicity and a general decrease of smiling non-synchronicity during humorous sequences. More specifically, the percentage of time for behavior 2 represents more than doubles during humorous segments (Non-humor $=13 \%$, Humor $=29.6 \%$ ). The increase is much more substantial for behavior 1 (Non-humor $=15.8 \%$, Humor $=44.5 \%$ ).

On the other hand, the percentage of time for behavior 0 and behavior $і 11$ decreases during humorous segments $($ Behavior -1 : Non-humor $=44.2 \%$, Humor $=7.4 \%$; Behavior 0 : Non-humor $=26.8 \%$, Humor $=18.3 \%$ ). Overall, synchronic smiling behaviors occur $74.1 \%$ of the overall time during humorous segments, but only $28.8 \%$ of the time during non-humorous segments.

In both American and French data, the same pattern is observed: 
- The participants display a higher percentage of non-synchronic smiling behavior (-1 and 0 combined) when humor is not present (USA: 52.26\%; Fr: 71\%) and a lower percentage when humor is present (USA: $36.48 \%$; Fr: $25.7 \%$ )

- They display a higher percentage of synchronic smiling behavior (i.e. 1 and 2 combined) when humor is present (USA: $52.31 \%$; Fr: $74.1 \%$ ) and a lower percentage when humor is absent (USA: 37; Fr: $28.8 \%$ )

It is to be expected that the participants in both corpora should display a higher level of synchronic smiling behavior when humor is present. However, there is a significant discrepancy in percentages between the two corpora. The French participants display a higher level of both non-synchronic and synchronic smiles. And while they display more nonsynchronic smiling behavior (0 or -1) in non-humorous segments, they also display more synchronic smiles (1 and 2) than the American participants when humor is present.

\subsection{Analysis of the targets in humorous sequences}

\subsubsection{American data}

Here, only the distribution of the various targets will be analyzed and not their presence or absence. The reason(s) why such and such target is present or not would require a more deepened sequential analysis of the conversations and of the various topics addressed by the participants, which is not the purpose of this article.

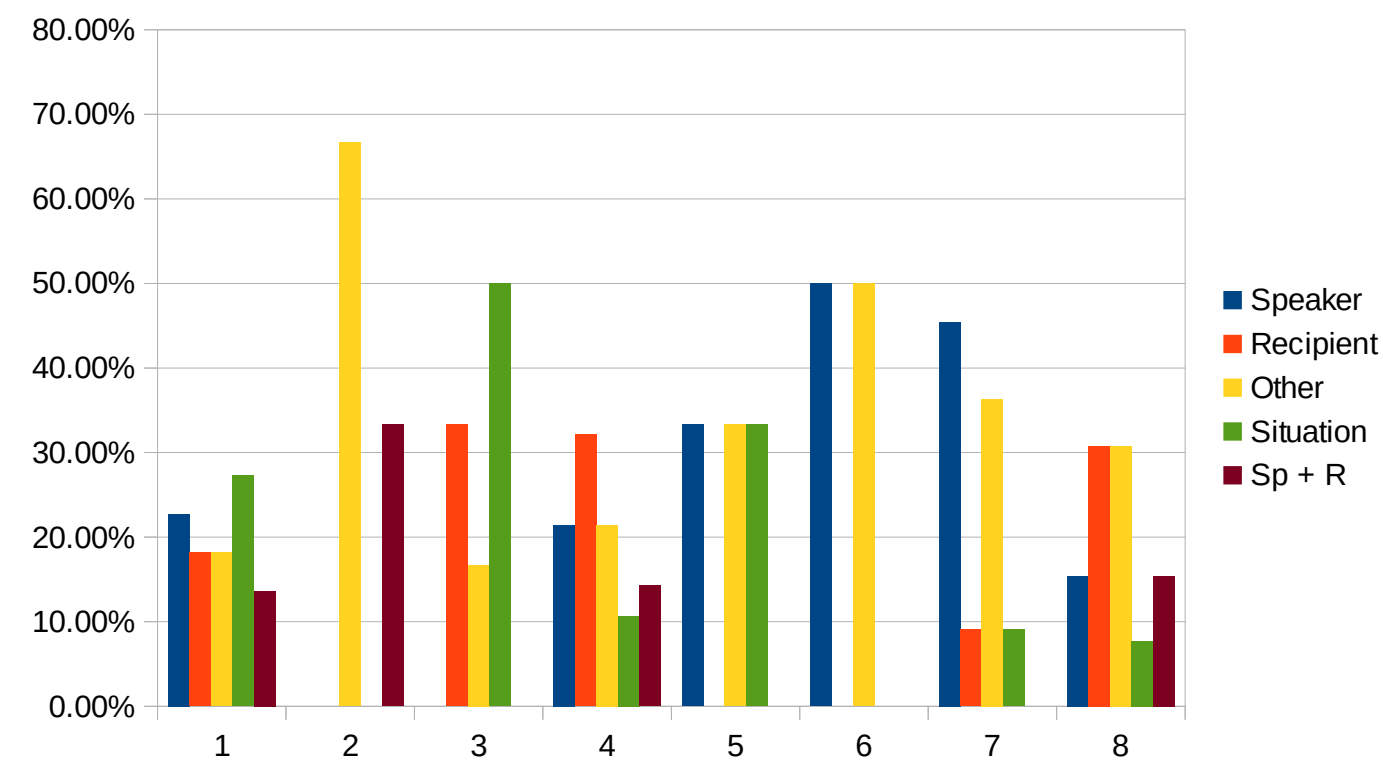

Figure 9. Distribution of the targets in each American interaction

All the targets are involved in the American data. However, significant variation can be observed depending on the interaction, both in terms of presence and proportion. Thus, ñSpeaker + Recipientò appears only in 4 interactions; ñRecipientò appears in 5 interactions, while ñSpeakerò and ñSituationò appear in 6 interactions. ñOtherò is the only target which appears in all the interactions. The differences in the proportion of each target can be linked to the presence or absence of one or the other. The high percentage of the targets ñSpeakerò and ñOtherò in interaction 6 can be explained by the fact they are the only ones mobilized. In other words, the more targets there are, the more the proportion of each of them decrease. 
Finally, it is worth noting that even if the target ñSpeaker + Recipientò is present in only half of the conversations, its presence not only increases the results obtained for ñSpeakerò and ñRecipientò themselves, but also could explain why these two last targets are not represented in the interaction 2 .

\subsubsection{French data}

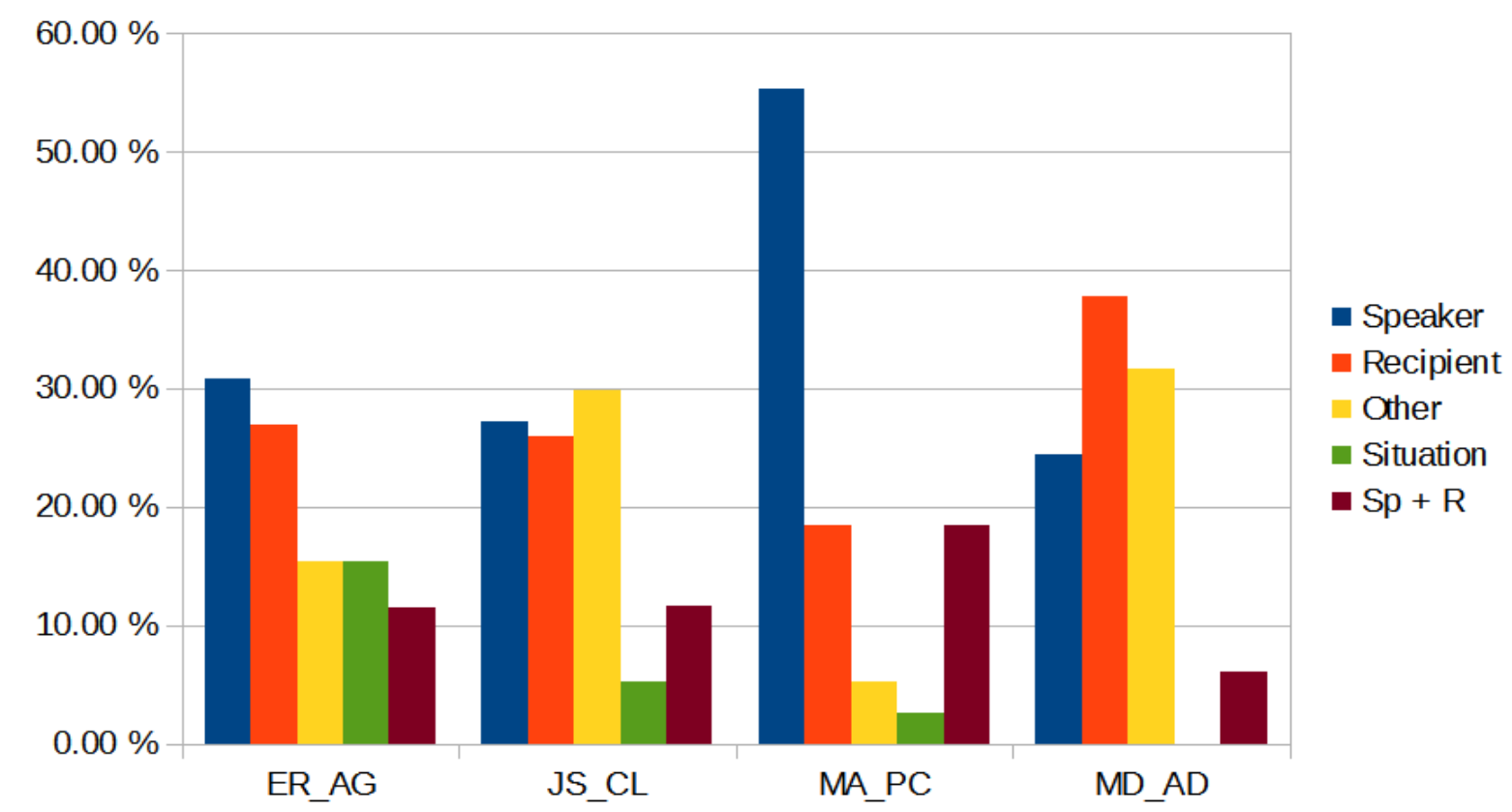

Figure 10. Distribution of the targets in each French interaction

A clarification concerning the French targets has to be made: the humorous utterances frequently had more than one target. Thus, in order to obtain a better overview of the data, the percentages of the targets were calculated taking only into account the first and principal target in such cases, leaving the layout and overlaps of the various targets for a separate and more detailed qualitative analysis. This methodological choice explains why ñSituationò does not appear in one interaction (MD_AD). It is actually present, but never as a principal one, as it is the case in the American data.

Even taking this absence into account, the distribution of the French targets seems more evenly distributed than in the American data. The major explanation for this is the link between the presence of a target and its distribution. As they are mainly all present, they are more evenly distributed. Despite this, discrepancies appear depending on the participants. For example, if ñ Speakerò and ñRecipientò are well-balanced in (ER_AG and JS_CL), MA_PC is quite surprising: ñSpeakerò is the target in more than the half of the humorous utterances $\ddot{i}$ and despite the fact that all the targets are present $\ddot{i}$ ñRecipientòrepresents $18.42 \%$ of the total amount.

The high proportion of ñOtherò should also be noted, as in the American data, but to a lesser extent. One possible explanation for this minor but systematical presence could be the better balanced distribution of the various targets in the French data. As noted above, the 
presence of ñ Speaker + Recipientò also increases the results obtained for ñSpeakerò and ñRecipientò respectively.

\subsection{Sequential analysis of some examples}

Although the distribution of the various targets displays some differences in the two data sets, the mechanisms used by the participants to produce humor are quite similar. As an example, for ñSpeaker + Recipientò in the following American example (8), shared laughter seems to be the more significant device: ñOtherò is known by both participants and explicitly named, as it will be shown in example (10) below.

$\begin{array}{lll}231 & M & \text { //i would sing OPera } \\ 232 & & \text { and MUSical theatre// } \\ 233 & & 0.723 \\ 234 & & \text { //and everything// } \\ 235 & & 0.75 \\ 236 & J & \text { //oh WOW// } \\ 237 & & 0.143 \\ 238 & M & \text { //yeah// } \\ 239 & & 1.830((\text { M laughs })) \\ 240 & J & \text { //i couldn't carry a TUNE } \\ 241 & & \text { in a BUCKet// } \\ 242 & & 2.167((\text { M laughs throughout })) \\ 243 & J & \text { //wow that was really CORny// } \\ 244 & & 0.85((M \text { clears throat })) \\ 245 & M & \text { //yeAH// } \\ 246 & & 2.100 \text { ((both laughing }))\end{array}$

In lines 240-241, J makes a self-disparaging joke about her inability to sing, at the end of a fairly long series of turns in which $\mathrm{M}$ has elaborated on her singing credentials ( $\mathrm{M}$ is a music major). After $\mathrm{M}$ displays an extensive laughter reaction, which overlaps the long pause (> 2 seconds), J produces a negative self-assessment, obviously soliciting a negative response, which would be a positive assessment of her joke. $M$ instead surprises her by agreeing, in clear violation of politeness expectations, and both speakers ratify the joke by another extended turn of laughter, this time jointly (246).

(9) $\quad$ PC $55 \quad$ t'aimerais parler de quoi

órhat would you like to speak aboutô

MA $\quad 47 \quad * d u$

áboutô

PC\56_\{voix souriante\}ducours@@desémantique@@+@@@dece matin@@@

ó smiling voice $\}$ the semantics class @ @ + @ @ of this 


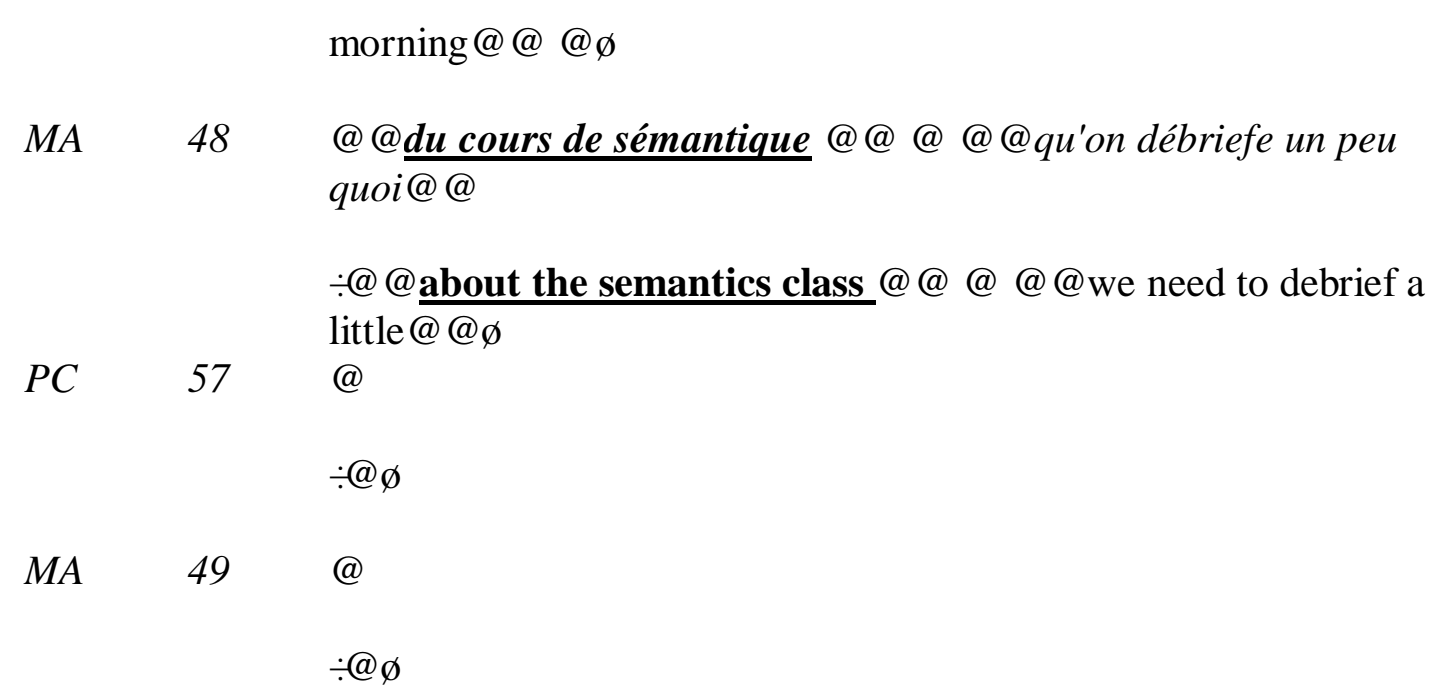

In (9), an example of ñSpeaker + Recipientò in the French data, just after the canned jokes sequence, PC asks about a first topic of conversation (55). Then, she frames her proposition (the class they both share) with a smiling voice, and more precisely, while laughing, the semantics class they had in the morning. MA (48), overlapping her and also laughing, proposes the same class. Although it is not transcribed here, the two participantsô final laughter reveals a common agreement on both the topic and the humorous frame to develop it. This laughter indicates a common shared understanding between the participants who are ñn the same boatò with respect to this specific class they do not understand very well.

\begin{tabular}{|c|c|c|}
\hline 150 & & 1.539 ((both laughing)) \\
\hline & $M$ & $/ / i$ wonder who wrote those JOkes// \\
\hline 152 & & 0.738 \\
\hline 153 & $J$ & //I don't know// \\
\hline 154 & & $2.16(($ J laughs $))$ \\
\hline 155 & $M$ & //anyway// \\
\hline 156 & & ??? \\
\hline 157 & $J$ & //PRObably Sal// \\
\hline 158 & & 0.849 \\
\hline 159 & $M$ & //PRObably// \\
\hline 160 & & 0.178 \\
\hline 161 & $M$ & I/maybe they're like \\
\hline 162 & & funny in Italy or something// \\
\hline
\end{tabular}

In (10), an example of ñOtherò in American data, $\mathrm{J}$ and $\mathrm{M}$ have just finished telling one of the jokes provided by the researcher and they are laughing at their ironical appreciation of the joke, initiated by $\mathrm{J}$, several turns before. Both $\mathrm{J}$ and $\mathrm{M}$ agree that the joke is bad and $\mathrm{J}$ and $\mathrm{M}$ are bonding by ironically pretending to appreciate the joke. $\mathrm{M}$ then switches the target to an unspecified third person (151) and then J targets a specific person (the researcher who had provided the jokes, ñSalò). Here, the other person is clearly named because this person is known to the two participants, which facilitates their agreement to laugh jointly at him (153, 160) 
(11)

CL』102 et euh+ @ @en fait j'avais même pas compris sa question@@ parce qu'elle me regarde et elle me dit alors vous avez pris quoi pour la raclette

ánd uh+ @@@in fact Ididnâ even understand her question@@ because she looks at me and she says to me so what did you take for the racletteô

CL $\quad 103$ et ben

ávellô

CL_104@@ @du fromage et d(e)la charcut quoi@ @

ó@@well some cheese and some deli meats [of course]@@ô

JS@86@@ @ fromage@@

ó@@cheese@@ô

In (11), an example of ñOtherò in the French data, it is not transcribed here but, like in the American corpus, the target is known and named by both participants. However, the tonality of the humor produced is quite different. In the French data, it is clearly more aggressive because it is produced in order to reveal (or maybe denounce) an absurdity. CL reports on

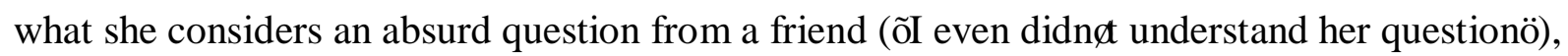
and the answer she proposes, laughingly, highlights this absurdity (CL 104). Both this opinion and the humorous frame are accepted by JS who repeats the term ñcheeseò, laughing too.

\section{Concluding remarks}

We have presented the first results of a larger project on a cross-cultural comparison of smiling behavior and humor in two different languages and cultures: American English and French. In this article, two phenomena have been examined: participantsô smiling behavior and the various targets involved in a humorous utterance. Two kinds of humor have been also investigated: canned jokes and conversational humor.

The participantsô smiling behaviors were compared in the two corpora in various ways. Both smiling behavior and synchronic smiling behavior were investigated in all the conversations as a whole, without distinguishing between humorous and non-humorous sequences. Then this parameter was also integrated, including in the canned joke sequences. Without taking into account the presence or absence of humor, the data show that the participants display all kinds of smiling behaviors, from the more asynchronic (behavior 0) to the more synchronic (behavior 2), with the French corpus showing more homogeneous results. Comparing the participantsôsmiling behaviors with the presence or absence of humor, the same pattern emerges in the two corpora: the presence of humor correlates with the display of smiling synchronic behaviors of participants (behaviors 1 and 2), while the absence of humor correlates with the display of more asynchronic smiling behavior or non-smiling behavior (behaviors 0 and -1). This result is not only consistent with the previous studies 
carried out on the two data separately (Gironzetti et al. 2016; Gironzetti, Attardo, and Pickering 2016 for the American data and Priego-Valverde and Bigi 2016; Priego-Valverde 2017, for the French data), but it also highlights a similar impact of the presence or absence of humor in both cultures. Furthermore, the comparison between the two data emphasizes the link between humor and smile. It also reveals an important difference between the two datasets: the French participants display a higher level of both non-synchronic and synchronic smiling behaviors. And although they display more non-synchronic and non-smiling behavior (0 or -1$)$ in non-humorous segments, they also display more synchronic smiling behaviors (1 and 2) than the American participants when humor is present. The reasons could be various. Considering, as previously said in section 5.1, that there are no significant differences in humor performance across the video chat and the face-to-face conditions, two other reasons remain possible. The first one is of course cultural and a deepened sequential analysis of both corpora would be relevant. The second one concerns the nature of the target, hypothesizing that according to its nature (five are present here: the speaker, the recipient, another absent person, the situation, or the speaker + the recipient), participants do not display the same smiling behavior.

Another contribution has been made concerning both the targets themselves and their links with the smiling behaviors of the participants. In this article, all the targets were categorized by a systematic analysis of each example of the two data. Focusing on conversational humor, five targets were analyzed in the two data: the speaker, the recipient, another absent person, the situation and both the speaker and the recipient. The results show major discrepancies in the two data-sets concerning the presence of each target, and, by extension, their distribution. Although all the targets are present in the American data-set, they do not all appear in each conversation. Only two targets are involved in two conversations while all five of them appear only in three. A heterogeneous distribution of the targets follows: the more targets that are involved, the more even is their distribution. The French data shows a more even distribution of the target overall. Here too, all of them are present in the whole corpus and just one (the situation) is absent in one interaction. This result may weight in favor of the hypothesis according to which the nature of the targets may affect the participantsôsmiling behaviors.

Finally, two targets (ñSpeakerò + Recipientò, ñOtherò) were more specifically analyzed in a short sequential analysis of some examples in the two data sets. While the comparison shows a difference in terms of the tonality of humor used (more aggressive in the French data), the two data sets illustrate that the same devices were used to produce humor: shared laughter with the target ñSp + Rò, and the target ñOò, not only known to both participants but also explicitly named.

While this first comparative study between American English and French highlights some important results, it also opens the door to many possibilities which need to be pursued and deepened. First of all, the analysis of the French corpus should be expanded to include data from the remaining seven interactions because only 4 have been analyzed on the basis of a data of 11 interactions. Secondly, this enrichment of the data would allow a statistical analysis of the potential correlations between the nature of the target and the participantsô smiling behaviors. Thirdly, focusing on participantsôsmiling behaviors and the distinction between genuine smiles or not (Duchenne vs. non-Duchenne smiles) may be relevant. As an 
example, distinguishing between the two of them as a reaction to humor could allow for the investigation of successful humor vs. failed humor. Finally, a deeper comparative sequential analysis of conversational humor needs to be pursued. Indeed, taking into account more parameters of analysis like the relationship between the participants could explain the discrepancies between American and French participants concerning both their nonsynchronic and non-smiling behavior in non-humorous segments, and their synchronic smiling behaviors in humorous segments.

\section{References}

Argyle, Michael. 1988 [1975]. Bodily communication. London: Methuen.

Attardo, Salvatore. 1994. Linguistic Theories of Humor. Berlin: Mouton de Gruyter.

Attardo, Salvatore. 2001. Humorous Texts: A Semantic and Pragmatic Analysis. Berlin: Mouton de Gruyter.

Attardo, Salvatore. 2012. Smiling, laughter, and humor. In Paulo Santangelo (ed.), Laughing in Chinese, 421ï 436. Rome: Aracne.

Attardo, Salvatore, Lucy Pickering \& Amanda Baker. 2011. Prosodic and multimodal markers of humor in conversation. Pragmatics and Cognition 19(2). $2241 \ddot{1} 247$.

Attardo, Salvatore, Lucy Pickering, Fofo Lomotey \& Shigehito Menjo. 2013. Multimodality in conversational humor. Review of Cognitive Linguistics 11(2). 400-414.

Attardo, Salvatore \& Victor Raskin. 1991. Script theory revis(it)ed: joke similarity and joke representation model . Humor 4(3/4). 293 ï 347.

Bavelas, Janet, Jennifer Gerwing \& Sara Healing. 2014. Including facial gestures in gesturespeech ensembles. In Seyfeddinipur, Mandana \& Marianne Gullberg (eds.), From Gesture in Conversation to Visible Action as Utterance: Essay in honor of Adam Kendon, 15ï 34. John Benjamins.

Béal, Christine \& Kerry Mullan. 2013. Issues in Conversational Humour from a Crosscultural Perspective: Comparing French and Australian Corpora. In Bert Peeters, Kerry \& Christine Béal (eds), Cross-culturally Speaking, Speaking Cross-culturally 107-139. Cambridge Scholars Publishing.

Béal, Christine \& Kerry Mullan. 2017. The pragmatics of conversational humour in social visits: French and Australian English. Language and Communication 55, 24-40.

Bigi, Brigitte. 2015. SPPAS - Multi-lingual Approaches for the Automatic Annotation of Speech. The Phonetician 111ї 112(2015-I-II). 54 ï 69.

Bigi, Brigitte \& Jorane Saubesty. 2015. Searching and retrieving multi-levels annotated data. In Gaëlle Ferré and Mark Tutton (eds.), Proceedings of Gesture and Speech in Interaction. September 2015, Nantes, France. https://hal.archives-ouvertes.fr/hal$\underline{01195646}$

Boersma, Paul. 2002. Praat, a system for doing phonetics by computer. Glot International $5(9 / 10)$.

Brugman, Hennie \& Albert Russel. 2004. Annotating multimedia/multimodal resources with ELAN. In Maria Teresa Lino, Maria Francisca Xavier, Fôtima Ferreira, Rute Costa and Raquel Silva (eds.), Proceedings of the fourth International Conference on Language Resources and Evaluation (LREC 2004), 2065ï 2068. Paris: European Language Resources Association. 
Brunner, Lawrence J. 1979. Smiles can be back channels. Journal of Personality and Social Psychology 37(5). 728 ï 734.

Cappella, Joseph N. 1997. Behavioral and judged coordination in adult informal social interactions: Vocal and Kinesic Indicators. Journal of Personality and Social Psychology 72(1). 119 ï 131.

Chapman, Anthony J. \& Hugh Corrie Foot. 1996. Humour and Laughter: Theory, research and applications. London: Wiley.

Coates, Linda Jane. 1991. A collaborative Theory of Inversion: Irony in Dialogue. Victoria: University of Victoria MA Thesis.

Duncan, Starkey, Lawrence J. Brunner \& Donald W. Fiske. 1979. Strategy signals in faceï toï face interaction. Journal of Personality and Social Psychology 37(2). 301 ï 313.

Ekman, Paul. 2003. Darwin, deception, and facial expression. Annals of the New York Academy of Sciences, 1000 (1), 205-221.

Ekman, Paul. 2007. Emotions Revealed. New York: Henry Holt.

Ekman, Paul, Richard Sorenson \& Wallace Friesen. 1969. ñPan-cultural elements in facial displays of emotionò. Science 164(3875). $86 і ̈ 88$.

Elfenbein, Hillary Anger \& Nalini Ambady. 2002. ñOn the universality and cultural specificity of emotion recognition: A meta-analysisò. Psychology Bulletin 128(2). $203 \ddot{i} 235$.

Fusaroli, Riccardo \& Kristian Tylén. 2012. Carving language for social interaction: a dynamic approach. Interaction Studies 13(1). 10313123.

Gironzetti, Elisa. 2017. Prosodic and multimodal markers of humor. In Attardo, S. (Ed.), The Routledge Handbook of Language and Humor (pp. 400ï 413). London and Ney York: Routledge.

Gironzetti, Elisa, Salvatore Attardo \& Lucy Pickering. 2016. Smiling, Gaze, and Humor in Conversation: A Pilot Study. In Leonor Ruiz-Gurillo (ed.), Metapragmatics of humor: Current Research Trends, 235ï 254. Amsterdam: John Benjamins.

Gironzetti, Elisa \& Shigehito Menjo. 2014. Smiling as a Discourse Marker of Humor. Paper presented at the $2^{\text {nd }}$ Conference of the American Pragmatics Association (AMPRA), University of California, Los Angeles, 17 ï 19 October.

Gironzetti, Elisa, Lucy Pickering, Meichan Huang, Ying Zhang, Shigehito Menjo \& Salvatore Attardo. 2016. Smiling synchronicity and gaze patterns in dyadic humorous conversations. Humor: International Journal of Humor Research 29(2). 301 ï 324.

Haakana, Markku. 2010. Laughter and smiling: Notes on co-occurrences. Journal of Pragmatics 42(6). 1499ї 1512.

Heerey, Erin A. \& Helen M. Crossley. 2013. Predictive and reactive mechanisms in smile reciprocity. Psychological Science 24(8). 1446ï 1455.

Heerey, Erin A. \& Ann M. Kring. 2007. Interpersonal consequences of social anxiety. Journal of Abnormal Psychology 116(1). $125 \mathrm{Ï} 134$.

Hess, Ursula \& Patrick Bourgeois. 2010. You smile ï I smile: Emotion expression in social interaction. Biological Psychology 84(3). 514 ï 520.

Hay, Jennifer. 2001. The pragmatics of humor support. Humor ï International Journal of Humor Research 14(1): 55-82. 
Izard, Carroll E. 1997. Emotions and facial Expressions. A Perspective from Differential Emotions Theory. In James A. Russell \& José Miguel Fernández-Dols (eds.), The Psychology of Facial Expression, 57ï76. Cambridge, UK: Cambridge University Press.

Jefferson, Gail. 1979. A technique for inviting laughter and its subsequent acceptance declination. In George Psathas (ed.), Everyday language: Studies in ethnomethodology, 79ї 96. New York: Irvington.

Jensen, Mikael. 2015. Smile as feedback expressions in interpersonal interaction. International Journal of Psychological Studies 7(4). 9510105.

Kaukomaa, Timo, Anssi Peräkylä \& Johanna Ruusuvuori 2013. Turn-opening smiles: Facial expression constructing emotional transition in conversation. Journal of Pragmatics 55. $21 \mathrm{i} 42$.

Kotthoff, Helga. 2000. Gender and joking: On the complexities of womenô image politics in humorous narratives. Journal of Pragmatics 32(1). $55 \mathrm{I} 80$.

Lewis, Paul. 1989. Comic Effects. Interdisciplinary Approaches to Humor in Literature. Albany: State University of New York Press.

Morreall, John. 1983. Taking Laughter Seriously. Albany: State University of New York Press.

Morreall, John. 2001. Sarcasm, irony, wordplay, and humor in the Hebrew Bible: A response to Hershey Friedman. Humor: International Journal of Humor Research 14(3). $293 \mathrm{I}$ 301.

Niedenthal, Paula, Silvia Krauth-Gruber \& François Ric. 2006. Psychology of Emotion: Interpersonal, Experiential, and Cognitive Approaches. New York: Psychology Press.

Norrick, Neal R. 1993. Conversational Joking. Bloomington. Indiana University Press.

Paxton, Alexandra \& Rick Dale. 2013. Multimodal networks for interpersonal interaction and conversational contexts. In M. Knauff, M. Pauen, N. Sebanz, \& I. Wachsmuth (eds.), Proceedings of the 35th Annual Meeting of the Cognitive Science Society, $2735 \mathrm{II} 2740$. Austin, TX: Cognitive Science Society.

Priego-Valverde, Béatrice. 2003. Lôhumour dans la conversation familière: description et analyse linguistiques. Paris: LôHarmattan.

Priego-Valverde, Béatrice. 2017. Does smile can frame an utterance as humorous? An analysis of smiling behavior in conversations? Paper presented at iGestoôl7, International Conference on Gesture and Multimodality, Porto, Portugal, $2 \ddot{~} 3$ February.

Priego-Valverde, Béatrice \& Brigitte Bigi. 2016. Smiling behavior in humorous and non humorous conversations: a preliminary cross-cultural comparison between American English and French. Paper presented at the $28^{\text {th }}$ Conference of the International Society of Humor Studies (ISHS), Dublin, Ireland, 27 Juneï 1 July.

Raskin, Victor. 1985. Semantic Mechanisms of Humor. Dordrecht, Holland: D. Reidel Publishing Company.

Sacks, Harvey. 1974 [1989]. An analysis of the course of a jokeôs telling in conversation. In Bauman, Richard \& Joel Sherzer (eds.), Explorations in the ethnography of speaking, 337ï 353, Cambridge, UK: Cambridge University Press. 
Schulz, Thomas R. 1996 [1976]. A cognitive-developmental analysis of humour. In Chapman, Antony J. \& Hugh C. Foot (eds.), Humor and Laughter. Theory, Research and Applications. New Brunswick, NJ: Transaction Publishers, 11 ï 36.

Wild, Barbara, Michael Eyb, Mathias Bartels \& Wolfgang Grodd. 2003. Why are smiles contagious? An fMRI study of the interaction between perception of facial affect and facial movements. Psychiatry Research 123(1). $17 \mathrm{ï} 36$.

\section{Annexes}

\section{Conventions used for French transcriptions}

@: Laughter

@@word@@: Word produced while laughing

$\hat{\mathrm{y}}$ : Rising intonation

Underlined word: Overlap

*: inaudible

\section{Conventions used for American English transcriptions}

//: beginning or ending of a pause unit

Capital letters: prominent syllable

(( )): additional information like laughter, throat

???: inaudible

\section{Frog joke}

An engineer was crossing a road one day when a frog called out to him and said, ñf you kiss me, Iôl turn into a beautiful princess.ò

He bent over, picked up the frog and put it in his pocket. The frog spoke up again and said, ñf you kiss me and turn me back into a beautiful princess, I will stay with you for one week.ò

The engineer took the frog out of his pocket, smiled at it and returned it to the pocket. The frog then cried out, ñf you kiss me and turn me back into a princess, Iôl stay with you and do ANYTHING you want.ò

Again the engineer took the frog out, smiled at it and put it back into his pocket. Finally, the frog asked, ñWhat is the matter? Iôre told you Iôn a beautiful princess that Iôl stay with you for a week and do anything you want. Why wonâ you kiss me?ò

The engineer said, ñLook Iôm an engineer. I donâ have time for a girlfriend, but a talking frog, now thatô cool.ò

\section{Donkey joke}

A car was involved in an accident in a street. As expected a large crowd gathered. A newspaper reporter, anxious to get his story could not get near the car.

Being a clever sort, he started shouting loudly, "Let me through! Let me through! I am the son of the victim." 
The crowd made way for him.

Lying in front of the car was a donkey. 